\title{
Article
}

\section{Alkylated selenophene-based ladder-type monomers via a facile route for high performance thin-film transistor applications}

\author{
Zhuping Fei, Yang Han, Eliot Gann, Thomas Hodsden, Anthony Chesman, \\ Christopher R. McNeill, Thomas D. Anthopoulos, and Martin Heeney
}

J. Am. Chem. Soc., Just Accepted Manuscript • Publication Date (Web): 26 May 2017

Downloaded from http://pubs.acs.org on May 30, 2017

\section{Just Accepted}

"Just Accepted" manuscripts have been peer-reviewed and accepted for publication. They are posted online prior to technical editing, formatting for publication and author proofing. The American Chemical Society provides "Just Accepted" as a free service to the research community to expedite the dissemination of scientific material as soon as possible after acceptance. "Just Accepted" manuscripts appear in full in PDF format accompanied by an HTML abstract. "Just Accepted" manuscripts have been fully peer reviewed, but should not be considered the official version of record. They are accessible to all readers and citable by the Digital Object Identifier (DOI®). "Just Accepted" is an optional service offered to authors. Therefore, the "Just Accepted" Web site may not include all articles that will be published in the journal. After a manuscript is technically edited and formatted, it will be removed from the "Just Accepted" Web site and published as an ASAP article. Note that technical editing may introduce minor changes to the manuscript text and/or graphics which could affect content, and all legal disclaimers and ethical guidelines that apply to the journal pertain. ACS cannot be held responsible for errors or consequences arising from the use of information contained in these "Just Accepted" manuscripts. 
Alkylated selenophene-based ladder-type monomers via a facile route for high

\title{
performance thin-film transistor applications
}

\author{
Zhuping Fei, ${ }^{1}$ Yang Han, ${ }^{* 1,2}$ Eliot Gann,${ }^{3}$ Thomas Hodsden, ${ }^{1}$ Anthony Chesman, ${ }^{4}$ Christopher R. McNeill, ${ }^{3}$ \\ Thomas D Anthopoulos, ${ }^{2,5}$ Martin Heeney*,1 \\ 1 Dept. Chemistry and Centre for Plastic Electronics, Imperial College London, Exhibition Rd, London, SW7 2AZ, UK. \\ 2 Dept. Physics and Centre for Plastic Electronics, Imperial College London, Exhibition Rd, London, SW7 2AZ, UK. \\ 3 Dept. of Materials Science and Engineering, Monash University, Clayton, Victoria 3800, Australia. \\ 4 CSIRO Manufacturing, Bayview Ave Clayton, Victoria 3168, Australia. \\ 5 Division of Physical Sciences and Engineering, King Abdullah University of Science and Technology, Thuwal 23955-6900, Saudi \\ Arabia.
}

\begin{abstract}
:
We report the synthesis of two new selenophene containing ladder-type monomers, cyclopentadiselenophene (CDS) and indacenodiselenophene (IDSe), via a twofold and fourfold Pd catalyzed coupling with a 1,1-diborylmethane derivative. Co-polymers with benzothiadiazole (BT) were prepared in high yield by Suzuki polymerization to afford co-polymers which exhibited excellent solubility in a range of non-chlorinated solvents. The CDS co-polymer exhibited a band gap of just $1.18 \mathrm{eV}$, which is amongst the lowest reported for donor-acceptor polymers. Thin-film transistors were fabricated using environmentally benign, non-chlorinated solvents with the CDS and IDSe co-polymers exhibiting hole mobility up to 0.15 and $6.4 \mathrm{~cm}^{2} / \mathrm{Vs}$, respectively. This high performance was achieved without the undesirable peak in mobility often observed at low gate voltages due to parasitic contact resistance.
\end{abstract}

\section{INTRODUCTION}

The past three decades has seen tremendous effort devoted to the development of conjugated small molecules and polymers for low-cost, flexible and large-area electronics. ${ }^{1,2}$ A variety of building blocks have been developed and incorporated into conjugated architectures for high performance organic thin-film transistors (OTFT) and organic photovoltaics (OPV) applications. ${ }^{3-6}$ Amongst these building blocks, ladder-type fused aromatic monomers have attracted much interest because of their unique structures and intriguing electrical properties. Covalently flanked adjacent aromatic units force the ladder type monomer to adopt a near co-planar rigid conformation. ${ }^{7,8}$ The use of this kind of co-planar building block can potentially elongate the effective conjugation length, facilitating $\pi$-electron delocalization and decreasing the reorganizational energy, thus enhancing the intrinsic charge carrier mobility. ${ }^{9-11}$ Many of the high performance ladder-type monomers reported to date are thiophene-based, in which the thiophene units have been bridged by a variety of heteroatoms. In addition to their electronic effects, these bridging atoms are typically utilized to incorporate solubilizing groups to enable processability. For example, many polymers and small molecules based on cyclopentadithiophene (CDT) and indacenodithiophene (IDT) with carbon as bridging atom exhibit promising performance in solution processed high performance OTFTs ${ }^{12-16}$ and OPVs ${ }^{3}$. Different strategies have been employed to modify the structure of the ladder-type units to adjust the electronic energy levels and aggregation state of the resulting semiconductor, for example, replacing the bridging carbon with $\mathrm{Si}$ or $\mathrm{Ge}$ atom, or further extending the conjugation length by flanking with fused aromatic rings. ${ }^{7}$

Replacing the sulfur atom in the thiophene ring is another approach to control the properties of semiconducting molecules. The larger size of Se over S reduces overlap with the adjacent $\pi$-system and the 
resulting reduction in aromaticity of selenophene compared to thiophene increases the quinoidal character of the polymer backbone, which usually results in reduced band gap. ${ }^{17,18}$ The more polarizable Se can also enhance intermolecular interactions of conjugated backbones in some cases, and many different selenophene-containing conjugated polymers have been reported to give improved device performance, especially charge carrier mobility, over their thiophene contained analogues. ${ }^{18-34}$ One consequence of these changes is that selenophene containing polymers are often poorly soluble, and those that are soluble typically require the use of highly chlorinated, high boiling point solvents like 1,2-dichlorobenzene. However such solvents are very unattractive for processing due to their detrimental environmental impact and health hazards. ${ }^{35}$ In this respect, we were interested to develop new fused ladder-type selenophene monomers, since bridging position could be utilized to promote solubility in non-chlorinated solvents via the use of very long alkyl sidechains. However until now, there have been few examples of selenophene-based ladder-type building blocks reported, possibly due to the difficulty in the functionalization of selenophene compared to thiophene..$^{20,36-40}$ Of the limited selenophene containing ladder-type building blocks reported, it is noticeable that carbon bridged examples always incorporate a bridging phenylalkyl or phenylalkoxy groups as the solubilizing group. This is likely due to synthetic reasons, since Friedel-Crafts type ring closing reactions are utilized from the corresponding (stable) triaryl cations. However in many cases it is undesirable for device applications to utilize aromatic groups directly on the bridging carbon because of the rather large steric hindrance compared to simple linear alkyl groups. This can inhibit close packing of the polymer backbones, resulting in reduced device performance, particularly for transistor applications.

Here we report a facile route for the first reported preparation of the alkylated selenophene-based fused-ring ladder monomers, cyclopentadiselenophene (CPDS) and indacenodiselenophene (IDSe). We report their corresponding conjugated polymers PCPDSBT and PIDSeBT, by copolymerization with an electron acceptor unit 2,1,3-benzothiadiazole (BT). The resulting polymers exhibit excellent solubility in non-chlorinated solvents such as tetralin, and organic thin-film transistors fabricated from these solutions exhibit a saturated mobility up to $6.4 \mathrm{~cm}^{2} \mathrm{~V}^{-1} \mathrm{~s}^{-1}$. This is amongst the highest hole mobility values reported for devices fabricated from non-chlorinated solvents. ${ }^{35}$ Importantly, all optimized devices show clean transistor behavior without the fluctuations in the derived carrier mobility at low gate voltages that are apparent in numerous previous reports of high mobility polymers. ${ }^{41,42}$

\section{EXPERIMENTAL SECTION}

General: All reactions were carried out in oven-dried glassware under Ar using solvents and reagents as commercially supplied, unless otherwise stated. 2,1,3-Benzothiadiazole-4,7-bis(boronic acid pinacol ester) (6) was purified by recrystallization from hexane before use. (3,3'-Dibromo-[2,2'-biselenophene]-5,5'-diyl)bis(trimethylsilane) $\quad\left(\mathbf{1}^{43}\right.$, bis(4,4,5,5-tetramethyl-1,3,2-dioxaborolan-2-yl)methane ${ }^{44}, \quad$ 2,5-dibromoselenophene $\quad(7)^{45}$ and 1,4-dibromo-2,5-diiodobenzene (10) ${ }^{46}$ were synthesized by the reported methods. ${ }^{1} \mathrm{H}$ and ${ }^{13} \mathrm{C}$ NMR spectra were recorded on a Bruker AV-400 (400 MHz), using the residual solvent resonance of $\mathrm{CDCl}_{3}$ or $d_{2}$-1,1,2,2-tetrachloroethane and are given in ppm. Elemental Analysis was performed in a Thermo Scientific (Calro Erba) Elemental Analyser, configured for \% C, H, and N. Number-average ( $\mathrm{Mn})$ and weight-average $(\mathrm{Mw})$ molecular weight were determined by Agilent Technologies 1200 series gel permeation chromatography (GPC) running in chlorobenzene at $80^{\circ} \mathrm{C}$, using two PL mixed B columns in series, and calibrated against narrow polydispersity polystyrene standards. Matrix-assisted laser desorption/ionization time-of-flight (MALDI-TOF) mass spectrometry was performed on a Bruker ultrafleXtreme MALDI-TOF analyzer. Anthracene (or 2,5-dihydroxybenzoic acid) and myoglobin were used as the matrix and calibration internal 
standard respectively. Thermogravimetric analysis (TGA) was carried out using a PerkinElmer Pyris 1 TGA machine, with heating from 50 to $700{ }^{\circ} \mathrm{C}$ at a heating rate of $20{ }^{\circ} \mathrm{C} / \mathrm{min}$ under $\mathrm{N}_{2}$. Differential scanning calorimetry (DSC) was performed on a TA Instruments Discovery differential calorimeter at a scan rate of $10{ }^{\circ} \mathrm{C} /$ min from $0{ }^{\circ} \mathrm{C}$ to $300{ }^{\circ} \mathrm{C}$ under $\mathrm{N}_{2}$. UV-vis spectra were recorded on a UV-1601 Shimadzu UV-vis spectrometer. Photo Electron Spectroscopy in Air (PESA) measurements was recorded with a Riken Keiki AC-2 PESA spectrometer with a power setting of $10 \mathrm{nW}$ and a power number of 0.5. Samples for PESA were prepared on glass substrates by spin-coating. Atomic force microscope (AFM) images were obtained with a Picoscan PicoSPM LE scanning probe in tapping mode. Samples were prepared following the same procedures for fabrication of transistors, except that Au contacts, CYTOP dielectric and Al gate were not applied. DFT calculations were modeled using Gaussian at the B3LYP/6-31G* level. The side chains were modified to ethyl groups in order to simplify the calculations.

\section{OTFT (organic thin-film transistor) device fabrication.}

Solution of polymer was prepared by dissolving the polymer in tetralin at a concentration of $10 \mathrm{mg} / \mathrm{ml}$. Transistors were prepared by first thermally evaporating $\mathrm{Au}(40 \mathrm{~nm})$ onto glass substrates through a shadow mask to form bottom source/drain (S/D) electrodes, which were then treated with self-assembled monolayer (SAM) of pentafluorobenzenethiol (PFBT) to improve work function. The SAM treatment step was carried out by immersing the substrates with patterned Au electrodes in a solution containing 1:1000 of PFBT in ethanol for $30 \mathrm{~min}$ before rinsing off with plenty of ethanol to remove the excess materials and annealing at $100{ }^{\circ} \mathrm{C}$ for 15 min. Polymer was then spin coated at $1000 \mathrm{rpm}$ for $60 \mathrm{~s}$ on top of the substrates with PFBT-treated bottom electrodes. The obtained films were then thermally annealed at 200 or $270{ }^{\circ} \mathrm{C}$ for $30 \mathrm{~min}$ under nitrogen. A layer of 900-nm CYTOP (Asahi Glass, type CTL-809M) dielectric was then deposited on top of the polymer layer by spin coating at $2000 \mathrm{rpm}$ for $60 \mathrm{~s}$ followed by an annealing step at $100{ }^{\circ} \mathrm{C}$ for $30 \mathrm{~min}$. The transistor structure was then completed by thermally evaporating $50 \mathrm{~nm}$ Al gate electrodes through a shadow mask, resulting in the bottom contact, top gate architecture. The channel width and length of the final transistors were $1000 \mu \mathrm{m}$ and 30 or $40 \mu \mathrm{m}$, respectively. Transistor characterization was carried out under nitrogen using a Keithley 4200 parameter analyzer. Linear mobility was calculated according to the equation below:

$$
\mu_{\operatorname{lin}}=\frac{\mathrm{L}}{\mathrm{WC}_{\mathrm{i}} \mathrm{V}_{\mathrm{D}}}\left(\frac{\partial \mathrm{I}_{\mathrm{Dlin}}}{\partial \mathrm{V}_{\mathrm{G}}}\right)
$$

And saturation mobility was extracted from the slope of $I_{D}{ }^{1 / 2}$ vs. $V_{G}$ :

$$
\mu_{\text {sat }}=\frac{2 \mathrm{~L}}{\mathrm{WC}_{\mathrm{i}}}\left(\frac{\partial \sqrt{\mathrm{ID} \mathrm{sat}}}{\partial \mathrm{V}_{\mathrm{G}}}\right)^{2}
$$

Copper(I) thiocyante (CuSCN) was dissolved in diethyl sulfide at a concentration of $5 \mathrm{mg} / \mathrm{mL}$ and spun cast onto the substrates with pre-patterned Au electrodes at $5000 \mathrm{rpm}$ for 30s. The resulting CuSCN thin film was annealed at $100{ }^{\circ} \mathrm{C}$ for 30 min under nitrogen. Polymer solutions was then spun cast and annealed following the same procedures as for PFBT devices.

The deep trap densities $\left(\mathrm{N}_{\mathrm{tr}}\right)$ of OTFTs were determined from subthreshold swing $(\mathrm{S})$ according to the equation below: ${ }^{47,48}$

$$
\mathrm{N}_{\mathrm{tr}}=\frac{\mathrm{C}_{\mathrm{i}}}{\mathrm{e}^{2}}\left(\frac{\mathrm{eS}}{\mathrm{kT} \ln (10)}-1\right)
$$

where $\mathrm{e}$ is the elementary charge, $\mathrm{C}_{\mathrm{i}}$ the geometric capacitance of gate dielectric, $\mathrm{V}_{\text {on }}$ the onset voltage, $k$ the Boltzmann constant, $\mathrm{T}$ the measuring temperature and $\mathrm{S}$ the subthreshold swing.

The dielectric constant $(\varepsilon)$ of CYTOP was determined with capacitance-frequency (C-F) measurements performed on a parallel plate capacitor structure using an impedance analyser (Solartron1260). The data yielded 
a value for the dielectric constant of 2.14, which is in good agreement with the manufacturer's specification (2.0-2.1). The $\mathrm{C}_{\mathrm{i}}$ of CYTOP was then determined to be $2.10( \pm 0.09) \mathrm{nFcm}^{-2}$, according to the equation below:

$$
\mathrm{C}_{\mathrm{i}}=\frac{\varepsilon \varepsilon_{0}}{\mathrm{~d}}
$$

where $\varepsilon$ is the dielectric constant of CYTOP $(\varepsilon=2.14), \varepsilon_{0}$ the vacuum permittivity, and d the thickness of CYTOP dielectric layer $(\sim 900 \mathrm{~nm})$.

\section{GIWAXS:}

GIWAXS measurements were performed at the SAXS/WAXS beamline at the Australian Synchrotron. ${ }^{49}$ Two-dimensional scattering patterns were recorded on a Dectris Pilatus $1 \mathrm{M}$ detector with $11 \mathrm{keV}$ photons used to probe the samples. An angle of incidence close to the critical angle $\left(\sim 0.13^{\circ}\right)$ was used. The total exposure time was $3 \mathrm{~s}$, with the reported images a composite of three separate $1 \mathrm{~s}$ exposures taken with different lateral detector offsets to fill in the regions missed by gaps in the detector. A silver behenate standard was used to calibrate the sample-to-detector distance. Results were analysed using NIKA $2 \mathrm{D}^{50}$ implemented in IgorPro.

\section{Synthesis:}

4H-cyclopenta[1,2-b:5,4-b']bis(selenophene)

(3,3'-Dibromo-[2,2'-biselenophene]-5,5'-diyl)bis(trimethylsilane)

bis(4,4,5,5-tetramethyl-1,3,2-dioxaborolan-2-yl)methane

$\begin{array}{rlcr} & & & \\ \text { g. } & \text { g, } & 7.6 & \mathrm{mmol}),\end{array}$ bis(tri-tert-butylphosphine)palladium $(0.39 \mathrm{~g}, 0.76 \mathrm{mmol})$ were added into a $100 \mathrm{~mL}$ two neck round bottom flask under argon. Then pre-degassed dioxane $(40 \mathrm{~mL})$ and $8 \mathrm{M} \mathrm{KOH}(1.44 \mathrm{~mL}, 11.5 \mathrm{mmol})$ were added. The mixture was thoroughly degassed under argon, and stirred for $24 \mathrm{~h}$ at $30{ }^{\circ} \mathrm{C}$. Additional $\mathrm{KOH}(2.88 \mathrm{~mL}, 23.0$ mmol) was added into the mixture and the reaction was heated for $24 \mathrm{~h}$ at $60{ }^{\circ} \mathrm{C}$. Water $(30 \mathrm{~mL})$ was added, and the mixture extracted $(3 \times 50 \mathrm{~mL} \mathrm{DCM})$. The combined organics were dried by $\mathrm{MgSO}_{4}$, filtered and concentrated under reduced pressure. The residue was purified by silica gel chromatography (eluent: hexane) to afford a pale yellow solid $(1.21 \mathrm{~g})$. To the resulting solid in THF (30 mL) was added tetrabutylammonium fluoride (TBAF) $(5.7 \mathrm{~mL}$ of a $1 \mathrm{M}$ solution in THF, $5.7 \mathrm{mmol})$ dropwise at $0{ }^{\circ} \mathrm{C}$. After stirring at this temperature for $5 \mathrm{~min}$, the mixture was passed through silica gel plug $(5 \mathrm{~cm} \times 5 \mathrm{~cm})$ (eluent: hexane). The solvent was removed under reduced pressure and the residue was purified by silica gel chromatography (eluent: hexane) to afford a pale yellow solid $(0.77 \mathrm{~g}$, yield: $37 \%)$. ${ }^{1} \mathrm{H} \mathrm{NMR}\left(\mathrm{CDCl}_{3}, 400 \mathrm{MHz},\right) \delta(\mathrm{ppm}): 7.85(\mathrm{~d}, J=5.3$ $\mathrm{Hz}, 2 \mathrm{H}), 7.34$ (d, $J=5.3 \mathrm{~Hz}, 2 \mathrm{H}), 3.47$ (s, 2H); ${ }^{13} \mathrm{C} \mathrm{NMR}\left(\mathrm{CDCl}_{3}, 100 \mathrm{MHz}\right.$, $\delta(\mathrm{ppm}): 150.8,143.6,129.3,125.3$, 34.6. HRMS (EI)+ calculated for $\mathrm{C}_{9} \mathrm{H}_{6} \mathrm{Se}_{2}$ : 273.8800. Found: 273.8812 .

\section{4,4-dihexadecyl-4H-cyclopenta[1,2-b:5,4-b']bis(selenophene)}

$4 H$-cyclopenta[1,2-b:5,4-b']bis(selenophene) (0.33 g, $1.2 \mathrm{mmol}), 1$-bromohexadecane (0.81 g, $2.7 \mathrm{mmol})$ and KI ( $25 \mathrm{mg}, 0.15 \mathrm{mmol}$ ) were added into a $50 \mathrm{~mL}$ two neck round bottom flask under argon, then degassed DMSO (15 $\mathrm{mL})$ and freshly ground $\mathrm{KOH}(0.4 \mathrm{~g}, 7.1 \mathrm{mmol})$ were added. The mixture was stirred overnight at room temperature. Water $(40 \mathrm{~mL})$ was added and the mixture extracted $(3 \times 30 \mathrm{~mL}$ hexane $)$. The combined organics were dried by $\mathrm{MgSO}_{4}$, filtered and concentrated under reduced pressure. The residue was purified by silica gel chromatography (eluent: hexane) to afford a pale yellow solid (0.63 g, yield: $73 \%) .{ }^{1} \mathrm{H} \mathrm{NMR}\left(\mathrm{CDCl}_{3}, 400 \mathrm{MHz}\right.$, $\delta$ (ppm): $7.81(\mathrm{~d}, J=5.3 \mathrm{~Hz}, 2 \mathrm{H}), 7.15(\mathrm{~d}, J=5.3 \mathrm{~Hz}, 2 \mathrm{H}), 1.92-1.73(\mathrm{~m}, 4 \mathrm{H}), 1.42-1.02(\mathrm{~m}, 52 \mathrm{H}), 0.88-0.82(\mathrm{~m}$, $10 \mathrm{H}) ;{ }^{13} \mathrm{C} \mathrm{NMR}\left(\mathrm{CDCl}_{3}, 100 \mathrm{MHz}\right) \delta(\mathrm{ppm}): 159.0,141.2,129.4,123.9,55.6,37.7,32.0,30.0,29.7-29.6$ (overlapping C), 29.4, 24.3, 22.7, 14.1. TOF MS (ES)[M+H]: calculated for $\mathrm{C}_{41} \mathrm{H}_{71} \mathrm{Se}_{2}$ : 723.3881. Found: 723.3884 .

2,6-dibromo-4,4-dihexadecyl-4H-cyclopenta[1,2-b:5,4-b']bis(selenophene)

(4): To a solution of 
4,4-dihexadecyl-4H-cyclopenta[1,2-b:5,4-b']bis(selenophene) $(0.63 \mathrm{~g}, 0.87 \mathrm{mmol})$ in THF (30 mL) was added $\mathrm{N}$-bromosuccinimide (NBS) $(0.34 \mathrm{~g}, 1.9 \mathrm{mmol})$ in one portion at $0{ }^{\circ} \mathrm{C}$ and the mixture was stirred for $2 \mathrm{~h}$ in the absence of light. An aqueous saturated solution of $\mathrm{Na}_{2} \mathrm{SO}_{3}(20 \mathrm{~mL})$ was added to quench the reaction. The mixture was extracted with hexane $(3 \times 30 \mathrm{~mL})$. The combined organics were dried by $\mathrm{MgSO}_{4}$, filtered and concentrated under reduced pressure. The residue was purified by silica gel chromatography (eluent: hexane) to afford a pale yellow solid (0.70 g, yield: 91\%). ${ }^{1} \mathrm{H}$ NMR $\left(\mathrm{CDCl}_{3}, 400 \mathrm{MHz}\right.$, $\delta(\mathrm{ppm}): 7.11(\mathrm{~s}, 2 \mathrm{H}), 1.78-1.74(\mathrm{~m}, 4 \mathrm{H}), 1.30-$ $1.12(\mathrm{~m}, 52 \mathrm{H}), 0.88-0.82(\mathrm{~m}, 10 \mathrm{H}) ;{ }^{13} \mathrm{C} \mathrm{NMR}\left(\mathrm{CDCl}_{3}, 100 \mathrm{MHz}\right.$, $\delta(\mathrm{ppm}): 156.4,141.6,127.1,114.1,57.1,37.6$, 31.9, 29.9, 29.7-29.6 (overlapping C), 29.4, 29.3, 24.2, 22.7, 14.1. MALDI-TOF: $878.8\left(\mathrm{M}^{+}\right)$.

Poly[4,4-dihexadecyl-4H-cyclopenta[1,2-b:5,4-b']bis(selenophene)-2,6-diyl-alt-(2,1,3-benzothiadiazole)-4,7 -diyl] (PCPDSBT): A $5 \mathrm{~mL}$ high pressure microwave reactor tube was charged 2,6-dibromo-4,4-dihexadecyl-4H-cyclopenta[1,2-b:5,4-b']bis(selenophene) $\quad(88.8 \quad \mathrm{mg}, \quad 0.1 \quad \mathrm{mmol})$, 2,1,3-benzothiadiazole-4,7-bis(boronic acid pinacol ester) $(39.2 \mathrm{mg}, \quad 0.1 \mathrm{mmol})$, bis(tri-tert-butylphosphine)palladium $\left(1.0 \mathrm{mg}, 2 \times 10^{-3} \mathrm{mmol}\right)$ and 1 drop of Aliquat 336 . The tube was sealed and flushed with argon, and then degassed toluene $(1.5 \mathrm{~mL})$, degassed aqueous $2 \mathrm{M} \mathrm{K}_{2} \mathrm{CO}_{3}(0.4 \mathrm{~mL})$ were added. The solution was thoroughly degassed under argon, and the argon inlet was removed and the reaction heated 3 days at $120^{\circ} \mathrm{C}$ (oil bath temperature). After cooling to RT, the mixture was poured into a mixture of methanol $(50 \mathrm{~mL})$ and concentrated $\mathrm{HCl}(10 \mathrm{~mL})$. The precipitant was filtered through a Soxhlet thimble. The polymer was purified by Soxhlet extraction with methanol, acetone, hexane and chloroform. The chloroform solution was concentrated and precipitated into methanol, and the precipitant was filtered and dried under vacuum to afford PCPDSBT as a dark green solid ( $72 \mathrm{mg}$, yield: $83 \%$ ). GPC (chlorobenzene, $80^{\circ} \mathrm{C}$ ): $\mathrm{Mn}=75000 \mathrm{~g} / \mathrm{mol}$, $\mathrm{Mw}=158000 \mathrm{~g} / \mathrm{mol} ; \lambda \max ($ film $)=860 \mathrm{~nm} .{ }^{1} \mathrm{H}$ NMR $\left(d-1,1,2,2\right.$-tetrachloroethane, $\left.400 \mathrm{MHz}, 130{ }^{\circ} \mathrm{C}\right), \delta(\mathrm{ppm})$ : 8.16 (s, broad, 2H), 7.93 (s, broad, 2H), 2.13 (m, broad, 4H), 1.39-1.30 (m, broad, 52H), 0.98-0.95 (m, broad, 10H). Anal. calcd: $\left(\mathrm{C}_{47} \mathrm{H}_{70} \mathrm{~N}_{2} \mathrm{SSe}_{2}\right)$ n: C, 66.17; H, 8.27; N, 3.28. Found: C, 65.05; H, 8.16; N, 3.63.

(5-Bromoselenophen-2-yl)trimethylsilane (6): To a solution of 2,5-dibromoselenophene (10.8 g, $37.3 \mathrm{mmol})$ in THF $(100 \mathrm{~mL})$ at $-78^{\circ} \mathrm{C}$ was added a solution of $\mathrm{n}-\mathrm{BuLi}(15.7 \mathrm{~mL}$ of a $2.5 \mathrm{M}$ solution in hexane, $39.2 \mathrm{mmol})$ dropwise. After stirring for $20 \mathrm{~min}$ at this temperature, chlorotrimethylsilane $(5.7 \mathrm{~mL}, 44.8 \mathrm{mmol})$ was added in one portion. The mixture was allowed to warm to room temperature and water $(100 \mathrm{~mL})$ was added and extracted $\left(3 \times 100 \mathrm{~mL}\right.$ hexane). The combined organics were dried by $\mathrm{MgSO}_{4}$, filtered and concentrated under reduced pressure. The residue was purified by silica gel chromatography (eluent: hexane) to afford a pale yellow oil (8.6 g, yield: 82\%). ${ }^{1} \mathrm{H} \mathrm{NMR}\left(\mathrm{CDCl}_{3}, 400 \mathrm{MHz}\right.$, $\delta(\mathrm{ppm}): 7.30(\mathrm{dd}, J=3.7,1.2 \mathrm{~Hz}, 2 \mathrm{H}), 7.22(\mathrm{dd}, J=3.7,1.2$ $\mathrm{Hz}, 2 \mathrm{H}), 0.33$ (s, 9H); ${ }^{13} \mathrm{C}$ NMR $\left(\mathrm{CDCl}_{3}, 100 \mathrm{MHz}\right.$, $\delta(\mathrm{ppm}): 152.0,136.4,134.6,119.8,0.17$. HRMS (EI)+ calculated for $\mathrm{C}_{7} \mathrm{H}_{11} \mathrm{BrSeSi}$ : 281.8979. Found: 281.8968 .

(5,5'-(2,5-Dibromo-1,4-phenylene)bis(4-bromoselenophene-5,2-diyl))bis(trimethylsilane) (8): To a solution of (5-bromoselenophen-2-yl)trimethylsilane $(3.6 \mathrm{~g}, 12.8 \mathrm{mmol})$ in THF $(100 \mathrm{~mL})$ at $-78{ }^{\circ} \mathrm{C}$ was added a solution of lithium diisopropylamide (LDA) $(7.7 \mathrm{~mL}$ of a $2 \mathrm{M}$ solution in THF/heptanes/ethylbenzene, $15.4 \mathrm{mmol})$ dropwise. The mixture was stirred for $1 \mathrm{~h}$ at this temperature, and then warmed to $-40{ }^{\circ} \mathrm{C}$ for $20 \mathrm{~min}$. $\mathrm{ZnCl}_{2}(24$ $\mathrm{mL}$ of $0.7 \mathrm{M}$ in THF, $16.8 \mathrm{mmol}$ ) was added dropwise and stirred at this temperature for $30 \mathrm{~min}$. Then the mixture was allowed to warm to $0{ }^{\circ} \mathrm{C}$ for $1 \mathrm{~h}$ and room temperature for $30 \mathrm{~min}$. 1,4-dibromo-2,5-diiodobenzene $(2.5 \mathrm{~g}, 5.1 \mathrm{mmol})$ and $\mathrm{Pd}\left(\mathrm{PPh}_{3}\right)_{4}(295 \mathrm{mg}, 0.26 \mathrm{mmol})$ were added, and the mixture was heated to $65{ }^{\circ} \mathrm{C}$ overnight. The mixture was cooled and passed directly through silica gel plug $(5 \mathrm{~cm} \times 5 \mathrm{~cm})$ (eluent: THF). The solvent was removed under reduced pressure and the residue was purified by silica gel chromatography (eluent: hexane, then DCM/hexane = 1/1), followed by recrystallization from ethyl acetate to afford white solid $(2.52 \mathrm{~g}$, yield: $62 \%$ ). ${ }^{1} \mathrm{H} \mathrm{NMR}\left(\mathrm{CDCl}_{3}, 400 \mathrm{MHz}\right.$, $\delta(\mathrm{ppm}): 7.68(\mathrm{~s}, 2 \mathrm{H}), 7.46(\mathrm{~s}, 2 \mathrm{H}), 0.36(\mathrm{~s}, 18 \mathrm{H}) ;{ }^{13} \mathrm{C} \mathrm{NMR}\left(\mathrm{CDCl}_{3}\right.$, $100 \mathrm{MHz},) \delta$ (ppm): 150.6, 143.8, 138.8, 138.0, 135.7, 122.5, 113.3, 0.03. Anal. calcd: $\mathrm{C}_{20} \mathrm{H}_{22} \mathrm{Br}_{4} \mathrm{Se}_{2} \mathrm{Si}_{2}$ : C, 30.17 ; 
H, 2.79. Found: C, 30.09; H, 2.86.

2,7-Bis(trimethylsilyl)-4,9-dihydro-s-indaceno[1,2-b:5,6-b']bis(selenophene)

(9):

5,5'-(2,5-Dibromo-1,4-phenylene)bis(4-bromoselenophene-5,2-diyl))bis(trimethylsilane) (6.5 g, $8.2 \mathrm{mmol}$ ), bis(4,4,5,5-tetramethyl-1,3,2-dioxaborolan-2-yl)methane $\quad\left(\begin{array}{lllll}6.6 & \mathrm{~g}, & 24.6 \quad \mathrm{mmol}) & \text { and }\end{array}\right.$ bis(tri-tert-butylphosphine)palladium $(0.63 \mathrm{~g}, 1.2 \mathrm{mmol})$ were added into a $250 \mathrm{~mL}$ two neck round bottom flask under argon. Then pre-degassed dioxane $(120 \mathrm{~mL})$ and $8 \mathrm{M} \mathrm{KOH}(3.1 \mathrm{~mL}, 24.8 \mathrm{mmol})$ were added. The mixture was thoroughly degassed under argon, and stirred for $24 \mathrm{~h}$ at $30^{\circ} \mathrm{C}$. Additional $\mathrm{KOH}(6.2 \mathrm{~mL}, 49.6 \mathrm{mmol})$ was added into the mixture and the reaction was heated $24 \mathrm{~h}$ at $60^{\circ} \mathrm{C}$. Water $(100 \mathrm{~mL})$ was added, and the mixture extracted $\left(3 \times 150 \mathrm{~mL}\right.$ hexane). The combined organics were dried by $\mathrm{MgSO}_{4}$, filtered and concentrated under reduced pressure. The residue was purified by silica gel chromatography (eluent: DCM/hexane $=1 / 2$ ) to afford an off-white solid (2.1 g, yield: $51 \%$ ). ${ }^{1} \mathrm{H} \mathrm{NMR}\left(\mathrm{CDCl}_{3}, 400 \mathrm{MHz}\right.$,) $\delta(\mathrm{ppm}): 7.58(\mathrm{~s}, 2 \mathrm{H}), 7.50(\mathrm{~s}, 2 \mathrm{H}), 3.69$ (s, $2 \mathrm{H}), 0.36$ (s, 18H); ${ }^{13} \mathrm{C} \mathrm{NMR}\left(\mathrm{CDCl}_{3}, 100 \mathrm{MHz}\right.$, $\delta(\mathrm{ppm}): 151.5,150.9,150.0,145.1,138.8,131.9,116.6,34.9$, 0.4. TOF MS (ES) $[\mathrm{M}+]$ : calculated for $\mathrm{C}_{22} \mathrm{H}_{26} \mathrm{Se}_{2} \mathrm{Si}_{2}$ : 505.9903. Found: 505.9915.

4,4,9,9-Tetrahexadecyl-4,9-dihydro-s-indaceno[1,2-b:5,6-b']bis(selenophene) (10): To a solution of 2,7-bis(trimethylsilyl)-4,9-dihydro-s-indaceno[1,2-b:5,6-b']bis(selenophene) $(0.51 \mathrm{~g}, 1.0 \mathrm{mmol})$ in anhydrous DMSO $(40 \mathrm{~mL})$ was added sodium tert-butoxide $(0.58 \mathrm{~g}, 6.0 \mathrm{mmol})$. The mixture was stirred at $70{ }^{\circ} \mathrm{C}$ for 30 min before 1-bromohexadecane $(1.9 \mathrm{~g}, 6.2 \mathrm{mmol})$ was added dropwise. The mixture was heated to $80{ }^{\circ} \mathrm{C}$ for overnight and poured into ice-water $(150 \mathrm{~mL})$. The precipitant was filtered and washed by water and methanol and dried under vaccum. The solid was purified by silica gel chromatography (eluent: hexane) to afford an off-white solid ( $0.77 \mathrm{~g}$, yield: 61 \%). 7.89 (d, $J=5.3 \mathrm{~Hz}, 2 \mathrm{H}), 7.23$ (s, 2H), 7.18 (d, $J=5.3 \mathrm{~Hz}, 2 \mathrm{H}), 1.99-1.83$ (m, 8H), $1.31-1.08$ (m, 104H), 0.89-0.78 (m, 20H); ${ }^{13} \mathrm{C} \mathrm{NMR}\left(\mathrm{CDCl}_{3}, 100 \mathrm{MHz},\right) \delta(\mathrm{ppm}): 156.8,152.2,144.4$, 138.0, 130.6, 124.2, 113.4, 54.9, 39.1, 31.9, 29.7, 29.7-29.6 (overlapping C), 29.4, 22.7, 14.1. MALDI-TOF: $1259.9\left(\mathrm{M}^{+}\right)$.

2,7-Dibromo-4,4,9,9-tetrahexadecyl-4,9-dihydro-s-indaceno[1,2-b:5,6-b']bis(selenophene) (11): $\quad$ To $\quad$ a solution of 4,4,9,9-tetrahexadecyl-4,9-dihydro-s-indaceno[1,2-b:5,6-b']bis(selenophene) (1.07 g, $0.85 \mathrm{mmol}$ ) in THF $(50 \mathrm{~mL})$ was added $N$-bromosuccinimide (NBS) $(0.32 \mathrm{~g}, 1.8 \mathrm{mmol})$ in one portion at room temperature and the mixture was stirred for $2 \mathrm{~h}$ in the absence of light. The mixture was poured into water $(200 \mathrm{~mL})$ and the precipitant was filtered and washed by water and methanol and dried under vacuum, followed by

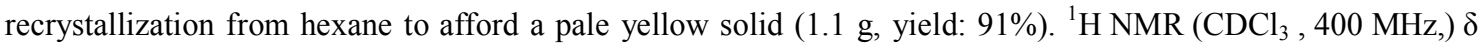
(ppm): 7.15 (s, 2H), 7.13 (s, 2H), $1.93-1.79$ (m, 8H), $1.31-1.08$ (m, 104H), 0.89-0.72 (m, 20H); ${ }^{13} \mathrm{C}$ NMR $\left(\mathrm{CDCl}_{3}, 100 \mathrm{MHz},\right) \delta$ (ppm): 155.2, 151.2, 145.2, 138.0, 127.5, 115.0, 113.3, 55.8, 39.0, 29.7, 29.7, 29.7-29.6 (overlapping C), 29.4, 23.9, 22.7, 14.1. MALDI-TOF: $1417.9\left(\mathrm{M}^{+}\right)$.

Poly[4,4,9,9-tetrahexadecyl-4,9-dihydro-s-indaceno[1,2-b:5,6-b']bis(selenophene)-2,7-diyl-alt-(2,1,3-benzot hiadiazole)-4,7-diyl] (PIDSeBT): A $20 \mathrm{~mL}$ high pressure microwave reactor tube was charged with 2,7-dibromo-4,4,9,9-tetrahexadecyl-4,9-dihydro-s-indaceno[1,2-b:5,6-b']bis(selenophene) (565.0 mg, 0.40 mmol), 2,1,3-benzothiadiazole-4,7-bis(boronic acid pinacol ester) (154.9 mg, $0.40 \mathrm{mmol}), \mathrm{Pd}_{2}(\mathrm{dba})_{3}(5.5 \mathrm{mg}, 6 \times$ $\left.10^{-3} \mathrm{mmol}\right), \mathrm{P}-(\mathrm{o}-\mathrm{tol})_{3}(7.3 \mathrm{mg}, 0.024 \mathrm{mmol})$ and 3 drops of Aliquat 336 . The tube was sealed and flushed with argon, and then degassed toluene $(10 \mathrm{~mL})$ and degassed aqueous $1 \mathrm{M} \mathrm{Na}_{2} \mathrm{CO}_{3}(2 \mathrm{~mL})$ were added. The solution was thoroughly degassed under argon, and the argon inlet was removed and the reaction heated 2 days at $120^{\circ} \mathrm{C}$ (oil bath temperature). After cooling to RT, the mixture was poured into a mixture of methanol $(100 \mathrm{~mL})$ and concentrated $\mathrm{HCl}(20 \mathrm{~mL})$. The precipitant was filtered through a Soxhlet thimble. The polymer was purified by Soxhlet extraction with methanol, acetone, hexane and chloroform. The chloroform solution was concentrated and precipitated into methanol, and the precipitant was filtered and dried under vacuum to afford PIDSeBT as a dark green solid (476 mg, yield: 86\%). GPC (chlorobenzene, $80^{\circ} \mathrm{C}$ ): $\mathrm{Mn}=119000 \mathrm{~g} / \mathrm{mol}, \mathrm{Mw}=303000 \mathrm{~g} / \mathrm{mol}$; 
$\lambda_{\max }($ film $)=725 \mathrm{~nm} .{ }^{1} \mathrm{H}$ NMR $\left(d-1,1,2,2\right.$-tetrachloroethane, $\left.400 \mathrm{MHz}, 130{ }^{\circ} \mathrm{C}\right), \delta(\mathrm{ppm}): 8.17(\mathrm{~s}$, broad, $2 \mathrm{H})$, 7.97 (s, broad, 2H), 7.45 (s, broad, 2H), 2.18-2.10 (m, broad, 8H), 1.40-1.26 (m, broad, 104H), 0.97-0.94 (m, broad, $20 \mathrm{H})$. Anal. calcd: $\left(\mathrm{C}_{86} \mathrm{H}_{138} \mathrm{~N}_{2} \mathrm{SSe}_{2}\right)$ n: C, $74.31 ; \mathrm{H}, 10.01 ; \mathrm{N}, 2.02$. Found: $\mathrm{C}, 74.15 ; \mathrm{H}, 10.15 ; \mathrm{N}, 2.14$.

\section{RESULTS AND DISCUSSION}

\section{Synthesis and characterization}

The most common routes to alkylated thiophene based ladder monomers of cyclopentadithiophene (CDT) and indacenodithiophene (IDT) usually involve alkylation of the methylene $\left(-\mathrm{CH}_{2}-\right)$ bridged precursor. However the synthesis of this key intermediate often involves relatively harsh reaction conditions, for example an acid catalyzed Freidel-Craft acylation, followed by reduction of the resulting ketone. ${ }^{51-54}$ Such sequences are usually low yielding for thiophene based materials, due to the high reactivity of thiophene under acidic conditions and due to difficulties in purifying the poorly soluble fused ketone intermediates. These routes thus appeared even more unattractive for the selenophene analogues, particularly given the higher reactivity of selenophene over thiophene. We therefore developed a route directly to the methylene bridged intermediates that avoided acidic conditions (Scheme 1), and utilized a Suzuki ring closing of a suitable di or tetrabromo derivative with bis(4,4,5,5-tetramethyl-1,3,2-dioxaborolan-2-yl)methane. ${ }^{44,55-58}$

Hence previously unknown cyclopentadiselenophene (CPDS, 2) was isolated in 37\% yield from 1, following ring closure with $\mathrm{Pd}\left[\mathrm{P}-(t-\mathrm{Bu})_{3}\right]_{2}$ in a mixture of dioxane/aqueous $\mathrm{KOH}$ with $\mathrm{Pd}\left[\mathrm{P}-(t-\mathrm{Bu})_{3}\right]_{2}$. In this case the crude product was directly desilylated with TBAF before isolation to avoid complications with partial loss of the trimethylsilyl groups during chromatography. Subsequent alkylation with 1-bromohexadecane followed by bromination with NBS afforded monomer material 4 in $66 \%$ over the two steps. Gratifyingly such an approach was even successful for the more challenging fourfold cross-coupling of tetrabromo derivative 8 (itself prepared from 2,5-dibromoselenophene in 3 steps in $51 \%$ yield) to afford the new 4,9-dihydro-s-indaceno[1,2-b:5,6-b']bis(selenophene) (IDSe) in 51\% yield. The higher yield compared to CPDS, despite the fourfold coupling, is likely related to the very electron rich nature of $\mathbf{1}$ compared to $\mathbf{8}$. This different electron density of the ring closed monomers is also reflected in the fact that the silylated IDSe was stable during chromatography, unlike CPDS which partially desilyated. The IDSe was readily alkylated with hexadecyl sidechains and brominated in an overall yield of $55 \%$. 


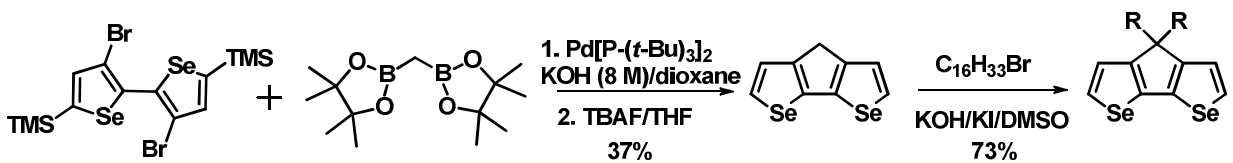
1

$37 \%$

2

3
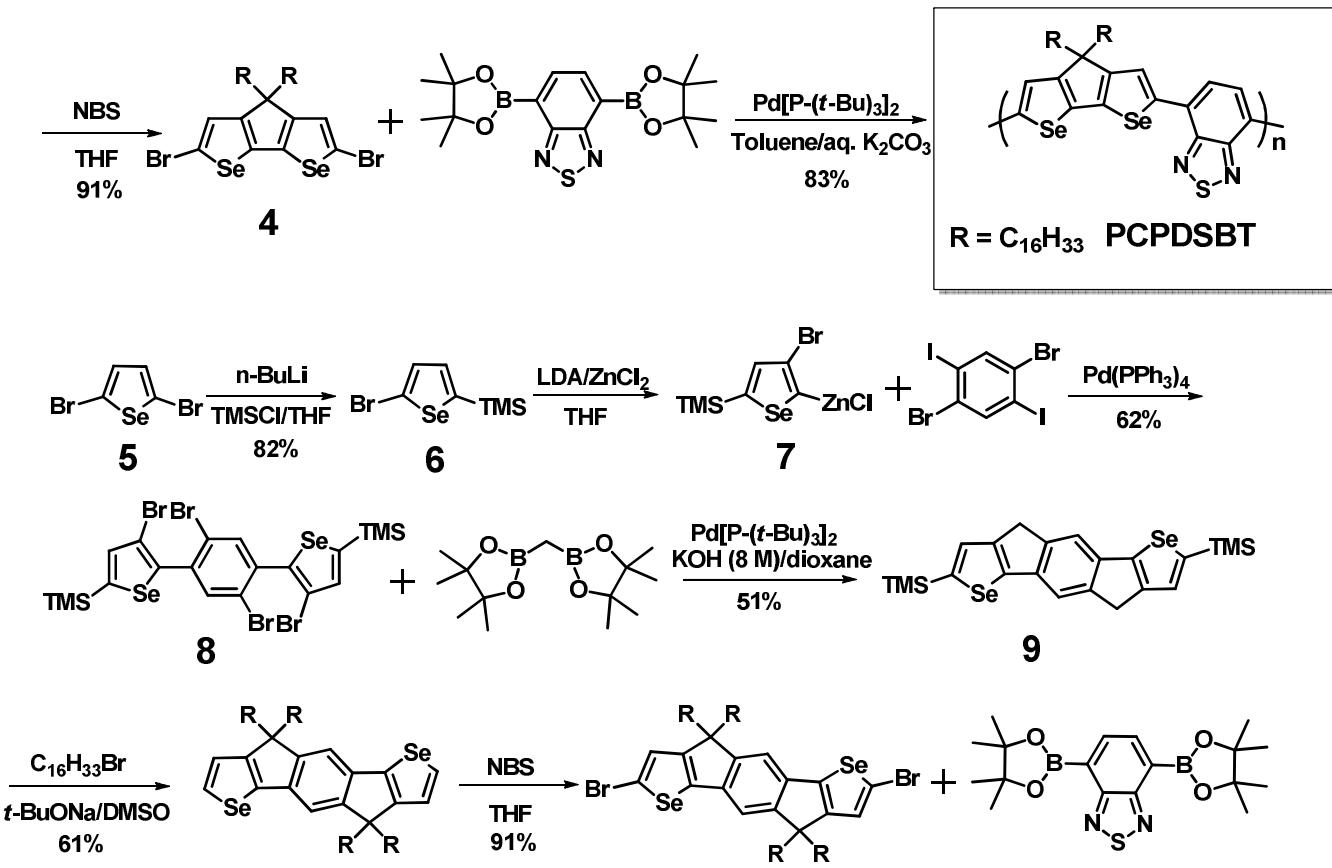

10

11

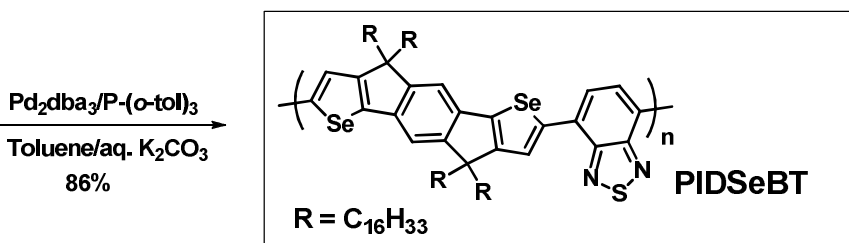

Scheme 1. The synthetic route to monomers and polymers.

Our initial attempts to prepare the copolymer of dibrominated CPDS (4) and 2,1,3-benzothiadiazole-4,7-bis(boronic acid pinacol ester) under standard Suzuki polymerization conditions with $\mathrm{Pd}\left(\mathrm{PPh}_{3}\right)_{4}$ or $\mathrm{Pd}_{2}(\mathrm{dba})_{3} / \mathrm{P}-(o \text {-tol })_{3}$ as the catalysts were unsuccessful. Only very low weight oligomer material was formed. We believed this related to problems with the oxidative addition of the catalyst to the very electron rich CPDS. Therefore use of the more reactive catalyst $\mathrm{Pd}\left[\mathrm{P}-(t-\mathrm{Bu})_{3}\right]_{2}$ enabled the successful isolation of polymeric material. Unlike PCPDSBT, PIDSeBT was readily prepared by $\mathrm{Pd}_{2}(\mathrm{dba})_{3} / \mathrm{P}-(o \text {-tol })_{3}$ as the catalyst under standard Suzuki polymerization conditions. Both polymers were purified by precipitation into acidic methanol followed by Soxhlet extraction with methanol, acetone, hexane and chloroform. PCPDSBT and PIDSeBT were obtained as dark green solids in yields of $83 \%$ and $91 \%$ respectively. Both polymers exhibited good solubility in common organic solvents, such as chloroform, toluene, chlorobenzene etc.

\section{Physical and optoelectronic properties}

Both PCPDSBT and PIDSeBT exhibited good thermal stabilities, as evaluated by thermal gravimetric analysis (TGA) (Figure S1a), with a 5\% weight loss at a temperature of 390 and $410{ }^{\circ} \mathrm{C}$ under nitrogen, respectively. Differential scanning calorimetry (DSC) curves (Figure S1b) of both polymers showed no obvious thermal transitions upon cycling between 0 and $300{ }^{\circ} \mathrm{C}$, suggesting, in agreement with many ladder polymers, 
(a)

that the backbone melting temperature is above $300{ }^{\circ} \mathrm{C}$. Density functional theory (DFT) calculations of trimers of PCPDSBT and PIDSeBT were modelled using Gaussian at the B3LYP/6-31G* level, with side-chains were modified to ethyl group for simplifying the calculations. The minimum-energy conformation of CPDSBT and IDSeBT trimers both show the polymers adopt almost coplanar backbones (Figure 1), potentially minimizing torsional disorder along the backbone. ${ }^{59}$ The minimum-energy conformation of CPDSBT also shows PCPDSBT has a slightly flexural geometry, which potentially hinders the charge transport along the backbone. ${ }^{60,61}$ However that of IDSeBT exhibits a more linear geometry, which may facilitate charge transport. Both the highest occupied molecular orbital (HOMO) and the lowest unoccupied molecular orbital (LUMO) of PCPDSBT are predicted to be delocalized over the entire backbones, whilst the HOMO of PIDSeBT is delocalized and the LUMO is mainly localized on acceptor unit (Figure S2 and S3).

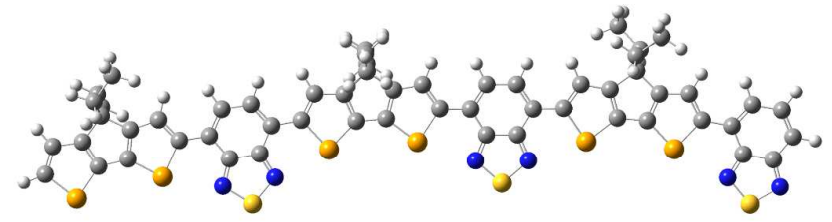

(b)

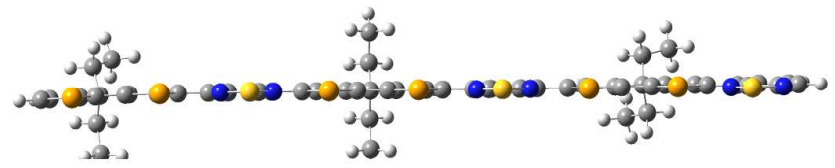

(c)

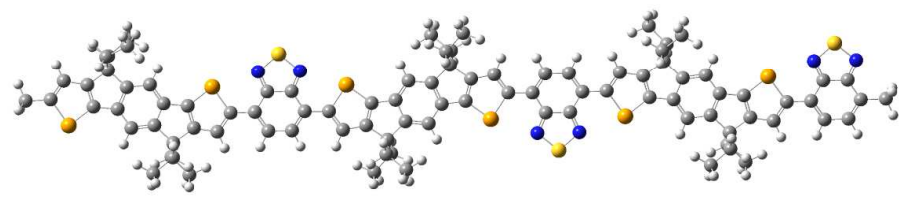

(d)

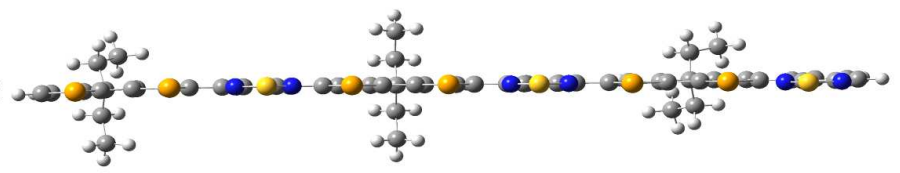

Figure 1. The energy-minimized structures of ethyl-substituted CPDSBT trimer (a) Top-view (b) Side-view and IDSeBT trimer (c) Top-view (d) Side-view. All calculated using DFT at the B3LYP/6.31G* level.

The UV-vis absorption spectra of PCPDSBT and PIDSeBT in dilute tetralin and as thin films are shown in Figure 2 and the data summarized in Table 1. PCPDSBT exhibits two main broad absorption bands in dilute tetralin, with a peak of $443 \mathrm{~nm}$ at high energy region which is assigned to $\pi-\pi^{*}$ transitions of the main backbone, and a peak of $860 \mathrm{~nm}$ with a shoulder of $806 \mathrm{~nm}$ in the low energy region which we attribute to an intramolecular charge transfer (ICT) from the CPDS donor to the BT acceptor. In film, the main peaks of PCPDSBT are red-shifted to 455 and $885 \mathrm{~nm}$, suggestive of backbone planarization and ordering in solid state. The long wavelength peak is red-shifted by around $135 \mathrm{~nm}$ compared to its thiophene analogue CDT-BT, ${ }^{62}$ further demonstrating the significant impact of selenophene substitution on the optical spectra. ${ }^{17,27,63-69}$ The absorption onset of PCPDSBT in the solid state is around $1050 \mathrm{~nm}$, corresponding to an optical band gap of $1.18 \mathrm{eV}$, which is amongst the lowest reported for donor-acceptor polymers. ${ }^{70-75}$ PIDSeBT also exhibits two main bands with peaks at 426, 650 and $705 \mathrm{~nm}$ in tetralin solution, and 434, 663 and $725 \mathrm{~nm}$ in the solid state. The absorption onset of PIDSeBT in the solid state is $780 \mathrm{~nm}$, corresponding to an optical band gap of $1.59 \mathrm{eV}$. The band gap of PCPDSBT is much smaller than that of PIDSeBT, which can be attributed to enhanced ICT from the stronger donor unit CPDS to the BT acceptor unit. The ionization potential (IP) of thin films of PCPDSBT and PIDSeBT were measured by photoelectron spectroscopy in air (PESA) to be 4.85 and $5.22 \mathrm{eV}$, respectively. The IP of PIDSeBT is around $0.18 \mathrm{eV}$ smaller than that of thiophene analogue measured by the 
same technique. ${ }^{54}$

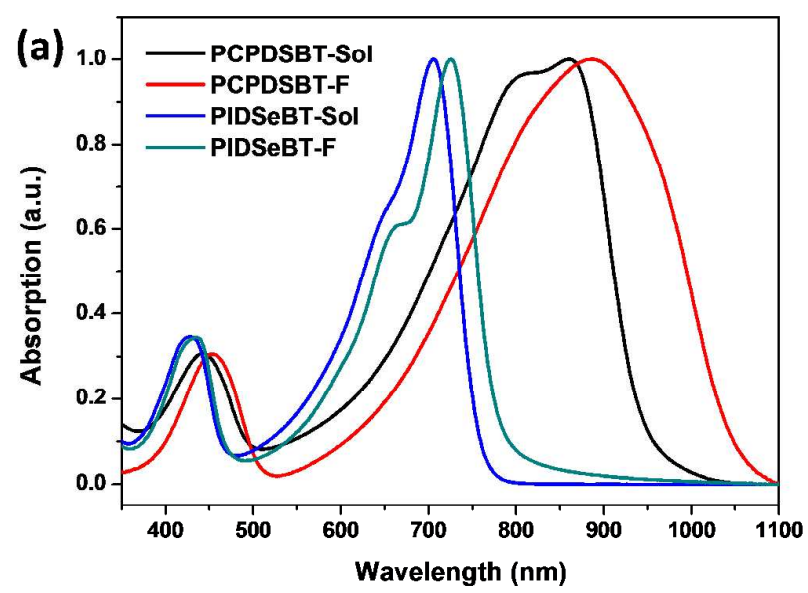

(b)

(c)

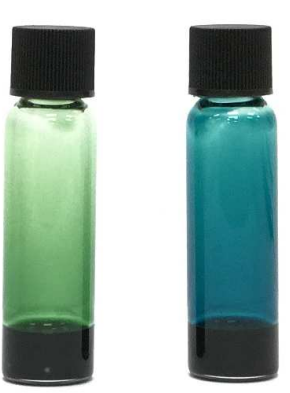

Figure 2. (a) UV-Vis absorption spectra of PCPDSBT and PIDSeBT in dilute tetralin and

as spun cast thin films; images of PCPDSBT (b) and PIDSeBT (c) in tetralin at $10 \mathrm{mg} / \mathrm{mL}$ at room temperature.

Table 1. Physical Properties of PCPDSBT and PIDSeBT.

\begin{tabular}{|c|c|c|c|c|c|c|c|c|}
\hline & $\begin{array}{c}\mathrm{Mn}^{\mathrm{a}} \\
\text { (KDa) }\end{array}$ & $\begin{array}{l}\mathbf{M w}^{\mathbf{a}} \\
(\mathrm{KDa})\end{array}$ & Đ & $\begin{array}{c}\text { UV-sol } \\
(\mathrm{nm})\end{array}$ & $\begin{array}{c}\text { UV-film } \\
\text { (nm) }\end{array}$ & $\begin{array}{l}\text { Onset } \\
(\mathrm{nm})\end{array}$ & $\begin{array}{r}E_{g, o p t} b \\
(e V)\end{array}$ & $\begin{array}{l}\text { I.P. }^{\mathrm{c}} \\
(\mathrm{eV})\end{array}$ \\
\hline PCPDSBT & 75 & 158 & 2.1 & $\begin{array}{c}443,806 \\
860\end{array}$ & $\begin{array}{l}455, \\
885\end{array}$ & 1050 & 1.18 & 4.85 \\
\hline PIDSeBT & 119 & 303 & 2.5 & $\begin{array}{c}426,650 \\
705\end{array}$ & $\begin{array}{c}434,663 \\
725\end{array}$ & 780 & 1.59 & 5.22 \\
\hline
\end{tabular}

${ }^{a}$ Measured using gel permeation chromatography (against polystyrene standards) in chlorobenzene at $80^{\circ} \mathrm{C}$. ${ }^{\mathrm{b}}$ Optical band gap estimated from the low energy band edge in the optical spectrum. ${ }^{c}$ Ionization potential measured by UV-PESA (error $\left.\pm 0.05 \mathrm{eV}\right)$.

\section{Thin-film Transistor Properties}

The charge transport properties of both polymers were assessed in bottom contact/top gate (BC/TG) TFTs. Importantly, both polymers were deposited from tetralin solutions, thereby avoiding the use of hazardous chlorinated solvents. Polymers were spin coated onto glass substrates equipped with pre-patterned Au source/drain electrodes, which were treated with the PFBT self-assembling monolayer to improve hole injection, followed by annealing at $200{ }^{\circ} \mathrm{C}$. Both PCPDSBT and PIDSeBT displayed dominant p-type behavior, with negligible hysteresis between the forward and reverse bias transfer characteristics (Figure 3 and S4). PCPDSBT exhibited the lower performance of the two polymers with average linear and saturation mobility of 0.10 and $0.14 \mathrm{~cm}^{2} \mathrm{~V}^{-1} \mathrm{~s}^{-1}$, respectively. Although these values are lower than those reported previously for best performing thiophene analogues, ${ }^{13,76-78}$ we note that these were only achieved with carefully optimized processing (chain alignment techniques) and molecular weight. In comparison, transistors based on PIDSeBT performed significantly better, with average linear and saturation mobility value of 0.56 and $1.6 \mathrm{~cm}^{2} \mathrm{~V}^{-1} \mathrm{~s}^{-1}$, respectively. 

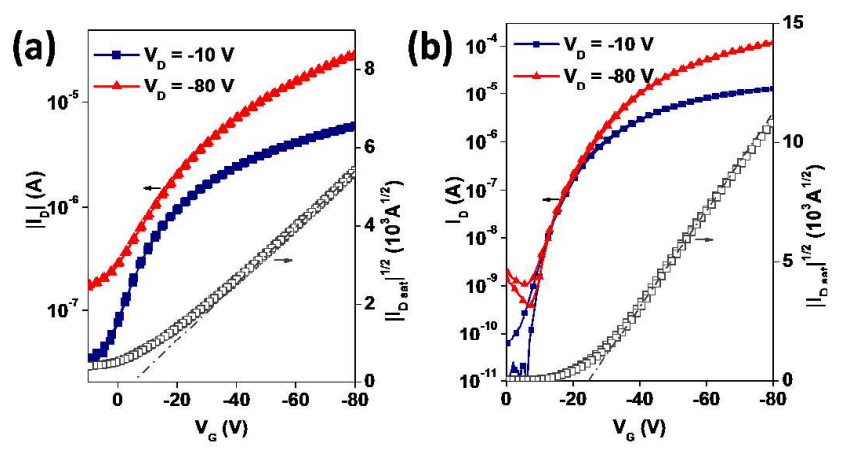

(c)

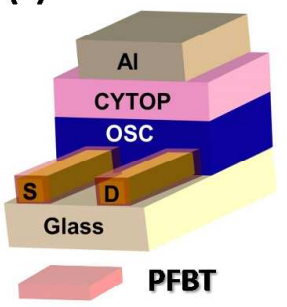

Figure 3. Typical transfer characteristics of BC/TG configuration OTFT device with PCPDSBT/PFBT (a) and

On the basis of these initial results we further optimized the PIDSeBT transistors via a combination of post-deposition thermal treatment and interfacial layer engineering. The use of a higher annealing temperature of $270{ }^{\circ} \mathrm{C}$ was found to enhance the performance (Table 2 and Figure S5), with the hole mobility, measured in saturation, now reaching $2.8 \mathrm{~cm}^{2} \mathrm{~V}^{-1} \mathrm{~s}^{-1}$. Interestingly, the threshold gate voltage in these devices was also found to increase by $7-8 \mathrm{~V}$, as compared to transistors annealed at $200{ }^{\circ} \mathrm{C}$, suggesting a higher injection barrier for holes, possibly a result of PFBT desorption from the Au electrode. In an effort to address this issue the PFBT monolayer was replaced with a thin layer of solution processed CuSCN. The role of the lateral material is twofold: firstly it provides a more thermally stable layer than PFBT, and secondly it acts as a highly effective electron blocking layer whilst enhancing hole injection. ${ }^{10,79,80}$ The transfer and output characteristics of the resulting OTFT are shown in Figure 4 and S5. The average saturation mobility of the PIDSeBT transistors featuring the CuSCN interlayer annealed at $200{ }^{\circ} \mathrm{C}$ was $1.8 \mathrm{~cm}^{2} \mathrm{~V}^{-1} \mathrm{~s}^{-1}$, a slightly higher value than that measured for the PFBT/Au based device annealed at the same temperature. However, devices annealed at $270{ }^{\circ} \mathrm{C}$ yielded a significantly higher hole mobility of $4.4 \mathrm{~cm}^{2} \mathrm{~V}^{-1} \mathrm{~s}^{-1}$ with a remarkable maximum value of 6.4 $\mathrm{cm}^{2} \mathrm{~V}^{-1} \mathrm{~s}^{-1}$. Notably, the linear mobilities of the CuSCN/Au device are significantly higher than those of PFBT/Au-based whilst the threshold voltages of former were lower than the latter - both indicating an improved matching between the work function of CuSCN/Au and the HOMO level of PIDSeBT. ${ }^{10}$ This was manifested by a threefold reduction in the contact resistance of the CuSCN/Au devices compared to that of PFBT/Au devices at $\mathrm{V}_{\mathrm{D}}=-80 \mathrm{~V}$ (Figure S6). We note that the mobility values obtained here are amongst the highest reported to date for polymers processed via spin coating from a non-chlorinated solvent without the use of any special alignment techniques. ${ }^{35}$ Most importantly, optimized devices exhibit excellent transfer characteristics without the undesirable peak in mobility often observed at low gate voltages due to parasitic contact resistance.

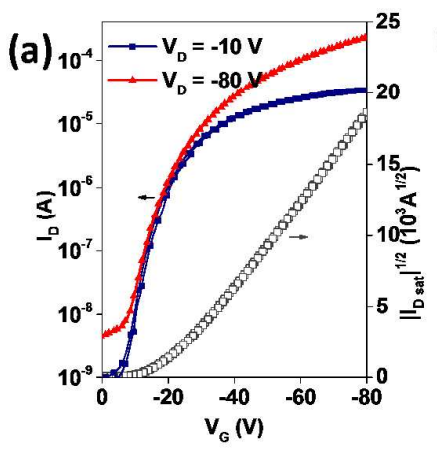

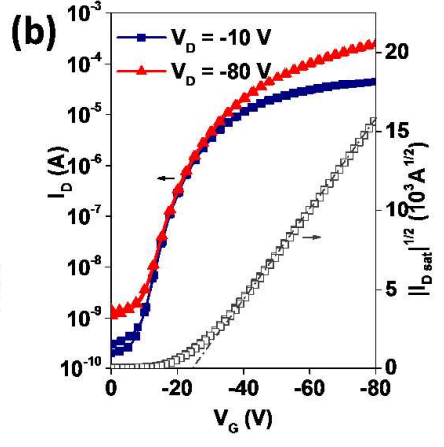

11 (c)

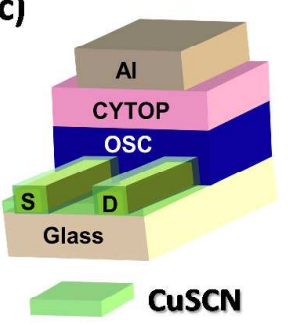


Figure 4. Typical transfer characteristics of BC/TG configuration OTFT device with PIDSeBT/CuSCN annealed at $200{ }^{\circ} \mathrm{C}$ (a) and $270^{\circ} \mathrm{C}$ (b). (c) The device structure employed.

Table 2. OTFT devices performance of PCPDSBT and PIDSeBT in bottom gate, top contact devices.

\begin{tabular}{|l|c|c|c|c|}
\hline $\begin{array}{l}\text { Polymer_annealing } \\
\left.\text { temperature ( }{ }^{\mathbf{O}} \mathbf{C}\right)\end{array}$ & $\begin{array}{c}\boldsymbol{\mu}_{\text {sat }} \text { average } \\
\left(\boldsymbol{\mu}_{\text {sat }} \mathbf{m a x}\right) \\
\left(\mathbf{c m}^{\mathbf{2}} \mathbf{V}^{-1} \mathbf{s}^{-1}\right)\end{array}$ & $\begin{array}{c}\boldsymbol{\mu}_{\text {lin }} \text { average } \\
\left(\mathbf{c m}^{\mathbf{2}} \mathbf{V}^{-1} \mathbf{s}^{-1}\right)\end{array}$ & $\mathbf{V}_{\text {Th }}(\mathbf{V})$ & $\mathbf{I}_{\text {on }} / \mathbf{I}_{\text {off }}$ \\
\hline PIDSeBT / PFBT_270 & $2.8(3.2)$ & 0.58 & -34.0 & $10^{5}-10^{6}$ \\
\hline PIDSeBT / CuSCN_270 & $4.4(6.4)$ & 1.8 & -24.8 & $10^{5}-10^{6}$ \\
\hline PIDSeBT / PFBT_200 & $1.6(1.7)$ & 0.56 & -26.9 & $10^{5}-10^{6}$ \\
\hline PIDSeBT / CuSCN_200 & $1.8(2.0)$ & 1.1 & -21.3 & $10^{5}-10^{6}$ \\
\hline PCPDSBT / PFBT_200 & $0.14(0.15)$ & 0.10 & -5.0 & $\sim 10^{2}$ \\
\hline
\end{tabular}

The subthreshold regime of the devices were also investigated to determine whether the performance improvement was due to decreasing trap density within the bulk film as a result of thermal annealing or the employment of the hole injection layer. The deep trap density in bulk film displayed negligible difference for all of PIDSeBT-based devices, in the range of (0.9-1.3) $\times 10^{12} \mathrm{eV}^{-1} \mathrm{~cm}^{-2}$ (Table S1). Thus the increase in mobility is most likely attributed to local changes at the semiconductor/dielectric interface and/or molecular rearrangement and the improved hole injection characteristics.

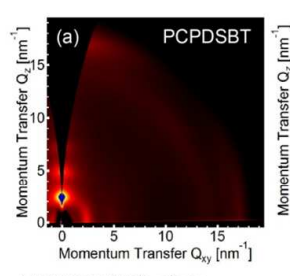

(d) PCPDSBT in-plane
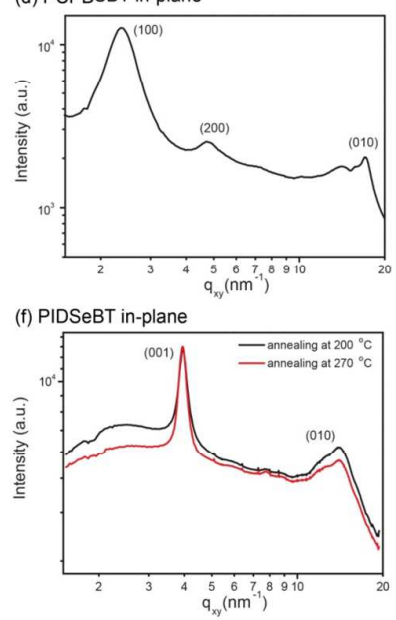

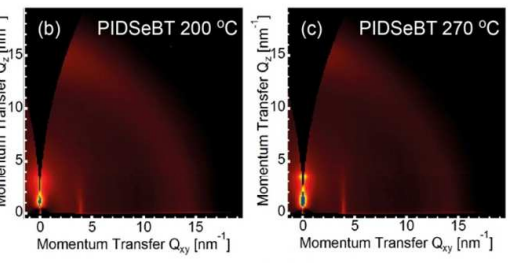

(e) PCPDSBT out-of-plane

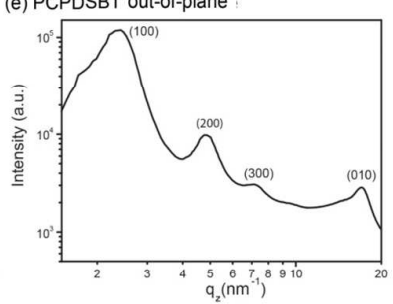

(g) PIDSeBT out-of-plane

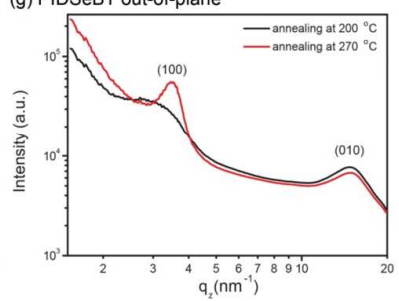

Figure 5. Two-dimensional GIWAXS images of PCDPSBT annealed at $200{ }^{\circ} \mathrm{C} \mathrm{(a),} \mathrm{PIDSeBT} \mathrm{annealed} \mathrm{at} 200$ ${ }^{\circ} \mathrm{C}$ (b), PIDSeBT annealed at $270{ }^{\circ} \mathrm{C}$ (c). Also shown are one-dimensional scattering profiles taken along the in-plane (d, f) and out-of-plane (e, g) directions for PCPDSBT (d, e) and PIDSeBT (f, g).

\section{Morphological Characterization}


The organization of polymer chains down to the molecular level was studied with grazing-incidence wide-angle X-ray scattering (GIWAXS), see Figure 5. The two-dimensional GIWAXS image of PCPDSBT is similar in many regards to that of CDT-BT. ${ }^{81,82}$ Three orders of alkyl (lamellar) stacking peaks are seen along $\mathrm{q}_{\mathrm{z}}$, with some alkyl stacking peaks also observed in-plane (along $\mathrm{q}_{\mathrm{xy}}$ ) indicating a mixture of 'edge-on' and 'face-on' oriented chains. The first-order lamellar stacking peak is observed at $\mathrm{q} \sim 2.4 \mathrm{~nm}^{-1}$ giving an alkyl stacking distance of $\sim 2.6 \mathrm{~nm}$ consistent with that found for CDT-BT. ${ }^{81} \mathrm{~A} \pi-\pi$ stacking peak is found at a value of $\mathrm{q} \sim$ $16.5 \mathrm{~nm}^{-1}$ corresponding to a $\pi-\pi$ stacking distance of $0.38 \mathrm{~nm}$, also consistent with values reported for CDT-BT ${ }^{81,82}$ The scattering pattern of PCPDSBT also shows a broad feature located at $\mathrm{q} \sim 14 \mathrm{~nm}^{-1}$ that is most intense at $\sim\left(\mathrm{q}_{\mathrm{x} y}, \mathrm{q}_{\mathrm{z}}\right)=\left(10 \mathrm{~nm}^{-1}, 10 \mathrm{~nm}^{-1}\right)$ which is associated with the ordered stacking of sidechains. ${ }^{81}$ Thus PCPDSBT is very similar in its packing to CDT-BT with the exchange of sulfur atoms for selenium atoms only slightly perturbing the microstructure. The lower OTFT performance of PCPDSBT observed here compared to values previous reported for CDT-BT may be due to sub-optimal processing ${ }^{82}$ with the mixture of face-on and edge-on components seen here less than ideal. Table 3 summarizes the crystallographic spacings and coherence lengths determined from the GIWAXS data.

Table 3. Crystallographic spacings and coherence lengths determined from the GIWAXS data.

\begin{tabular}{|l|c|c|c|c|c|c|}
\hline Polymer & $\begin{array}{c}(100) \\
\text { d-spacing } \\
(\mathrm{nm})\end{array}$ & $\begin{array}{c}(100) \\
\text { coherence } \\
\text { length (nm) }\end{array}$ & $\begin{array}{c}(010) \\
\text { d-spacing (nm) }\end{array}$ & $\begin{array}{c}(010) \\
\text { coherence } \\
\text { length (nm) }\end{array}$ & $\begin{array}{c}(001) \\
\text { d-spacing (nm) }\end{array}$ & $\begin{array}{c}(001) \\
\text { coherence } \\
\text { length (nm) }\end{array}$ \\
\hline PCPDSBT & 2.60 & 13.4 & 0.38 & 9.1 & - & - \\
\hline $\begin{array}{l}\text { PIDSeBT } \\
\left(\mathbf{2 0 0}{ }^{\circ} \mathbf{C}\right)\end{array}$ & - & - & 0.42 & 2 & 1.59 & 18.8 \\
\hline $\begin{array}{l}\text { PIDSeBT } \\
\left(\mathbf{2 7 0}{ }^{\circ} \mathbf{C}\right)\end{array}$ & 1.79 & 10.6 & 0.42 & 2 & 1.59 & 21.6 \\
\hline
\end{tabular}

In contrast to PCPDSBT, PIDSeBT shows a very different molecular packing. The 2D GIWAXS images of the PIDSeBT films are characterized by a prominent backbone stacking (001) peak located in-plane at $\mathrm{q}=3.95$ $\mathrm{nm}^{-1}$. This peak is distinguished from an alkyl stacking peak by its narrow, vertical shape, and corresponds to a backbone repeat distance of $1.59 \mathrm{~nm}$. A weak alkyl stacking peak is seen in the out-of-plane direction, corresponding to a d-spacing of $\sim 1.8 \mathrm{~nm}$ which is very different to the much larger spacing seen for PCPDSBT. The $\pi-\pi$ stacking distance of PIDSeBT is found to be $\sim 0.42 \mathrm{~nm}$, slightly larger than the value measured for IDT-BT. $^{54}$ The shorter lamellar spacing and larger $\pi-\pi$ spacing of PIDSeBT compared to PCPDSBT indicates that PIDSeBT adopts a completely different side-chain packing geometry. Indeed, the rigid, planar nature of the PIDSeBT backbone promotes backbone ordering over side-chain ordering. High degrees of order in lamellar stacking have been shown not to be necessary for high charge transport mobility, with polymers such as IDT-BT demonstrating exceptionally low degrees of energetic disorder attributed to their backbone planarity. ${ }^{59}$ With the increase in annealing temperature from $200{ }^{\circ} \mathrm{C}$ to $270{ }^{\circ} \mathrm{C}$ the crystalline features of PIDSeBT become sharper, notably the backbone stacking peak, which helps to understand the increase in mobility with annealing in terms of improved order along the polymer backbone. 
(a)

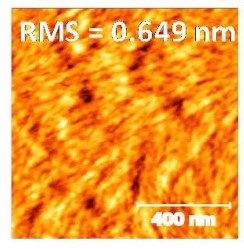

(b)

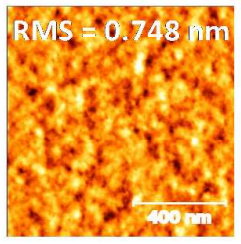

(c)

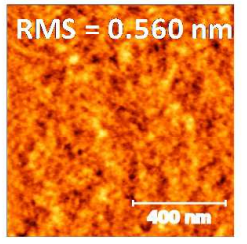

(d)

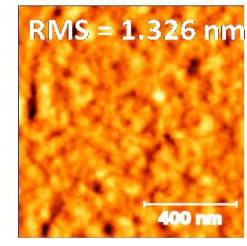

(e)

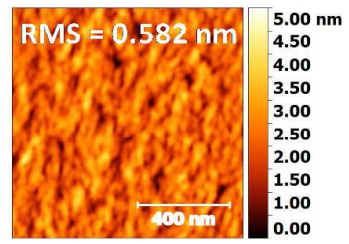

Figure 6. AFM topography images of polymer films: (a) PCPDSBT on glass annealed at $200{ }^{\circ} \mathrm{C}$, (b) PIDSeBT on glass annealed at $200^{\circ} \mathrm{C}$, (c) PIDSeBT on glass annealed at $270{ }^{\circ} \mathrm{C}$, (d) PIDSeBT on CuSCN surface annealed at $200{ }^{\circ} \mathrm{C}$, (e) PIDSeBT on CuSCN surface annealed at $270{ }^{\circ} \mathrm{C}$. All images are $1 \times 1 \mu \mathrm{m}^{2}$.

To probe the surface microstructures, the morphologies of the polymer semiconductor films were characterized by tapping mode AFM. Sample films were prepared under identical conditions to the OTFT fabrication except that no dielectric or gate electrodes were deposited. The topography and phase images of polymer films processed under different conditions are shown in Figure 6 and S7. PCPDSBT forms continuous and smooth film with fine fibrillar structures, affording surface roughness (root mean square, RMS) of $0.649 \mathrm{~nm}$ after annealing at $200^{\circ} \mathrm{C}$. PIDSeBT yielded films with less pronounced microstructural features, and a similar RMS of $0.748 \mathrm{~nm}$. The film turned modestly smoother after annealing at higher temperature of $270{ }^{\circ} \mathrm{C}$, with RMS of $0.560 \mathrm{~nm}$. Film cast atop $\mathrm{CuSCN}$ and annealed at $200{ }^{\circ} \mathrm{C}$ were rougher than that without interfacial layer, with a RMS of $1.326 \mathrm{~nm}$, due to the rather rough surface of crystalized CuSCN. ${ }^{83}$ The surface roughness decreased to $0.582 \mathrm{~nm}$ after annealing at $270{ }^{\circ} \mathrm{C}$ in agreement with the increase in transistor performance.

\section{CONCLUSION}

In conclusion, we have reported the synthesis of two novel selenophene containing ladder monomers by a twofold and fourfold $\mathrm{Pd}$ catalyzed ring closing reaction between bis(4,4,5,5-tetramethyl-1,3,2-dioxaborolan-2-yl)methane and the di- and tetrabrominated aryl precursors. This route, which avoids the necessity for harsh acidic or reducing conditions, allows the preparation of cyclopentadiselenophene (CDS) and indacenodiselenophene (IDSe) for the first time. Subsequent alkylation with long hexadecyl sidechains affords highly soluble monomeric materials, which were copolymerized with the electron acceptor benzothiadiazole. The resulting polymers PCPDSBT and PIDSeBT exhibit highly coplanar backbones in combination with excellent solubility in a range of non-chlorinated solvents. The optical band gap of PCPDSBT exhibits a significant red-shift compared to the well investigated thiophene analogue, with a small optical band gap of $1.18 \mathrm{eV}$, one of the lowest reported for a donor-acceptor co-polymer. Thin film transistors fabricated from tetralin solutions of both polymers exhibited p-type behavior, with PIDSeBT exhibiting a hole mobility up to $6.4 \mathrm{~cm}^{2} \mathrm{~V}^{-1} \mathrm{~s}^{-1}$ after device optimization. This is amongst the best reported transistor performance for a polymer fabricated from a non-chlorinated solvent. Importantly these devices exhibited excellent transfer characteristics without the undesirable peak in mobility often observed at low gate voltages due to parasitic contact resistance. These results demonstrate that the incorporation of selenophene into ladder type structures is a possible route to improve the performance of materials. In particular, given the interest in ladder type monomers for non-fullerene acceptor materials, we believe that this synthetic approach will be of further interest for the development of new types of acceptor backbone.

\section{ASSOCIATED CONTENT}




\section{Supporting Information}

This Supporting Information is available free of charge via the Internet at http://pubs.acs.org. TGA, DSC, Modeling, Transistor plots and AFM data (PDF).

\section{AUTHOR INFORMATION}

Corresponding Author

*m.heeney@imperial.ac.uk

*yang.han@imperial.ac.uk

ORCID

Martin Heeney: 0000-0001-6879-5020

Yang Han: 0000-0002-4638-7429

Zhuping Fei: 0000-0002-2160-9136

\section{NOTES}

Additional data relating to the paper can be found at dx.doi.org/10.6084/m9.figshare.5001965. The authors declare no competing financial interest.

\section{ACKNOWLEGMENTS}

We thank the British Council (Grant Number 173601536) and EPSRC (EP/L016702/1) for support. C.R.M. acknowledges support from the Australian Research Council (DP130102616). This research was undertaken in part on the SAXS/WAXS beamline at the Australian Synchrotron, Victoria, Australia.

\section{REFERENCES}

(1) Yi, Z.; Wang, S.; Liu, Y. Adv. Mater. 2015, 27, 3589.

(2) Lu, L.; Zheng, T.; Wu, Q.; Schneider, A. M.; Zhao, D.; Yu, L. Chem. Rev. 2015, 115, 12666.

(3) Chen, Q.; Zhang, Q. J. Mater. Chem. C 2017, 5, 1275.

(4) Guo, X.; Facchetti, A.; Marks, T. J. Chem. Rev. 2014, 114, 8943.

(5) Sirringhaus, H. Adv. Mater. 2014, 26, 1319.

(6) Zhang, L.; Cao, Y.; Colella, N. S.; Liang, Y.; Bre, J.; Briseno, A. L. Acc. Chem. Res. 2015, 48, 500.

(7) Wu, J.-S.; Cheng, S.-W.; Cheng, Y.-J.; Hsu, C.-S. Chem. Soc. Rev. 2015, 44, 1113.

(8) Holliday, S.; Donaghey, J.; McCulloch, I. Chem. Mater. 2014, 26, 647.

(9) He, M.; Li, W.; Gao, Y.; Tian, H.; Zhang, J.; Tong, H.; Yan, D.; Geng, Y.; Wang, F. Macromolecules 2016, $49,825$.

(10) Zhang, W.; Han, Y.; Zhu, X.; Fei, Z.; Feng, Y.; Treat, N. D.; Faber, H.; Stingelin, N.; McCulloch, I.; Anthopoulos, T. D.; Heeney, M. Adv. Mater. 2016, 28, 3922.

(11) Li, Y.; Yao, K.; Yip, H. L.; Ding, F. Z.; Xu, Y. X.; Li, X.; Chen, Y.; Jen, A. K.-Y. Adv. Funct. Mater. 2014, 24, 3631.

(12) Luo, C.; Ko, A.; Kyaw, K.; Perez, L. A.; Patel, S.; Wang, M.; Grimm, B.; Bazan, G. C.; Kramer, E. J.; Heeger, A. J. Nano Lett. 2014, 14, 2764.

(13) Yamashita, Y.; Hinkel, F.; Marszalek, T.; Zajaczkowski, W.; Pisula, W.; Baumgarten, M.; Matsui, H.; Müllen, K.; Takeya, J. Chem. Mater. 2016, 28, 420.

(14) Zhang, X.; Bronstein, H.; Kronemeijer, A. J.; Smith, J.; Kim, Y.; Kline, R. J.; Richter, L. J.; 
Anthopoulos, T. D.; Sirringhaus, H.; Song, K.; Heeney, M.; Zhang, W.; McCulloch, I.; DeLongchamp, D. M. Nat. Commun. 2013, 4, 2238.

(15) Lee, B. H.; Bazan, G. C.; Heeger, A. J. Adv. Mater. 2016, 28, 57.

(16) Lee, B. H.; Hsu, B. B. Y.; Patel, S. N.; Labram, J.; Luo, C.; Bazan, G. C.; Heeger, A. J. Nano Lett. 2016 , 16,314 .

(17) Fei, Z.; Ashraf, R. S.; Han, Y.; Wang, S.; Yau, C. P.; Tuladhar, P. S.; Anthopoulos, T. D.; Chabinyc, M. L.; Heeney, M. J. Mater. Chem. A 2015, 3, 1986.

(18) Ashraf, R. S.; Meager, I.; Nikolka, M.; Kirkus, M.; Planells, M.; Schroeder, B. C.; Holliday, S.; Hurhangee, M.; Nielsen, C. B.; Sirringhaus, H.; McCulloch, I. J. Am. Chem. Soc. 2015, 137, 1314.

(19) Kang, I.; Yun, H.; Chung, D. S.; Kwon, S.; Kim, Y. J. Am. Chem. Soc. 2013, 135, 14896.

(20) Intemann, J. J.; Yao, K.; Yip, H.; Xu, Y.; Li, Y.; Liang, P.; Ding, F.; Li, X.; Jen, A. K.-Y. Chem. Mater. 2013, 25, 3188 .

(21) Back, J. Y.; Yu, H.; Song, I.; Kang, I.; Ahn, H.; Shin, T. J.; Kwon, S. K.; Oh, J. H.; Kim, Y. H. Chem. Mater. 2015, 27, 1732.

(22) Zhao, Z.; Yin, Z.; Chen, H.; Zheng, L.; Zhu, C.; Zhang, L.; Tan, S.; Wang, H.; Guo, Y.; Tang, Q.; Liu, Y. Adv. Mater. 2017, 29, 1602410.

(23) Shahid, M.; McCarthy-Ward, T.; Labram, J.; Rossbauer, S.; Domingo, E. B.; Watkins, S. E.; Stingelin, N.; Anthopoulos, T. D.; Heeney, M. Chem. Sci. 2012, 3, 181.

(24) Kronemeijer, A. J.; Gili, E.; Shahid, M.; Rivnay, J.; Salleo, A.; Heeney, M.; Sirringhaus, H. Adv. Mater. 2012, 24, 1558.

(25) Jung, E. H.; Bae, S.; Yoo, T. W.; Jo, W. H. Polym. Chem. 2014, 5, 6545.

(26) Al-Hashimi, M.; Han, Y.; Smith, J.; Bazzi, H. S.; Alqaradawi, S. Y. A.; Watkins, S. E.; Anthopoulos, T. D.; Heeney, M. Chem. Sci. 2016, 7, 1093.

(27) Saadeh, H. a; Lu, L.; He, F.; Bullock, J. E.; Wang, W.; Carsten, B.; Yu, L. ACS Macro Lett. 2012, 1, 361.

(28) Hwang, Y.; Ren, G.; Murari, N. M.; Jenekhe, S. A. Macromolecules 2012, 45, 9056.

(29) Conboy, G.; Spencer, H. J.; Angioni, E.; Kanibolotsky, A. L.; Findlay, N. J.; Coles, S. J.; Wilson, C.; Pitak, M. B.; Risko, C. Mater. Horiz. 2016, 3, 333.

(30) Tsai, C.; Fortney, A.; Qiu, Y.; Gil, R. R.; Yaron, D.; Kowalewski, T.; Noonan, K. J. T. J. Am. Chem. Soc. 2016, 138, 6798.

(31) Gao, D.; Gibson, G. L.; Hollinger, J.; Li, P.; Seferos, D. S. Polym. Chem. 2015, 6, 3353.

(32) Yan, H.; Hollinger, J.; Bridges, C. R.; Mckeown, G. R.; Al-faouri, T.; Seferos, D. S. Chem. Mater. 2014, $26,4605$.

(33) Alghamdi, A. a. B.; Watters, D. C.; Yi, H.; Al-Faifi, S.; Almeataq, M. S.; Coles, D.; Kingsley, J.; Lidzey, D. G.; Iraqi, A. J. Mater. Chem. A 2013, 1, 5165.

(34) Sung, M. J.; Luzio, A.; Park, W. T.; Kim, R.; Gann, E.; Maddalena, F.; Pace, G.; Xu, Y.; Natali, D.; de Falco, C.; Dang, L.; McNeill, C. R.; Caironi, M.; Noh, Y. Y.; Kim, Y. H. Adv. Funct. Mater. 2016, 26, 4984.

(35) Cho, J.; Yu, S. H.; Chung, D. S. J. Mater. Chem. C 2017, 5, 2745.

(36) Chang, C. C.; Chen, C. P.; Chou, H. H.; Liao, C. Y.; Chan, S. H.; Cheng, C. H. J. Polym. Sci. Part A Polym. Chem. 2013, 51, 4550.

(37) Chang, H. H.; Tsai, C. E.; Lai, Y. Y.; Liang, W. W.; Hsu, S. L.; Hsu, C. S.; Cheng, Y. J. Macromolecules 2013, 46, 7715.

(38) Yao, K.; Intemann, J. J.; Yip, H.-L.; Liang, P.-W.; Chang, C.-Y.; Zang, Y.; Li, Z.; Chen, Y.; Jen, A. 
K.-Y. J. Mater. Chem. C 2014, 2, 416.

(39) Sulas, D. B.; Yao, K.; Intemann, J. J.; Williams, S. T.; Li, C. Z.; Chueh, C. C.; Richards, J. J.; Xi, Y.; Pozzo, L. D.; Schlenker, C. W.; Jen, A. K.-Y.; Ginger, D. S. Chem. Mater. 2015, 27, 6583.

(40) Li, Y.; Zhong, L.; Wu, F.-P.; Yuan, Y.; Bin, H.; Jiang, Z.-Q.; Zhang, Z.; Zhang, Z.-G.; Li, Y.; Liao, L. Energy Environ. Sci. 2016, 9, 3429.

(41) Mcculloch, B. I.; Salleo, A.; Chabinyc, M. Science 2016, 352, 1521.

(42) Bittle, E. G.; Basham, J. I.; Jackson, T. N.; Jurchescu, O. D.; Gundlach, D. J. Nat. Commun. 2016, 7, 10908.

(43) Getmanenko, Y. A.; Tongwa, P.; Timofeeva, T. V.; Marder, S. R. Org. Lett. 2010, 12, 2136.

(44) Xu, S.; Shangguan, X.; Li, H.; Zhang, Y.; Wang, J. J. Org. Chem. 2015, 80, 7779.

(45) Earmme, T.; Hwang, Y.; Murari, N. M.; Subramaniyan, S.; Jenekhe, S. A. J. Am. Chem. Soc. 2013, 135, 14960.

(46) Modjewski, M.; Lindeman, S. V; Rathore, R. Org. Lett. 2009, 11, 4656.

(47) Sze, S. M.; Ng, K. K. Physics of Semiconductor Devices, 3rd ed.; John Wiley \& Sons: New York, 2007, pp. 216.

(48) Lin, Y. H.; Faber, H.; Rossbauer, S.; Anthopoulos, T. D. Appl. Phys. Lett. 2013, 102, 193516.

(49) Kirby, N. M.; Mudie, S. T.; Hawley, A. M.; Cookson, D. J.; Mertens, H. D. T.; Cowieson, N.; Samardzic-Boban, V. J. Appl. Crystallogr. 2013, 46, 1670.

(50) Ilavsky, J. J. Appl. Crystallogr. 2012, 45, 324.

(51) Zhao, C.; Zhang, Y.; Ng, M. K. J. Org. Chem. 2007, 72, 6364.

(52) Zhong, H.; Han, Y.; Shaw, J.; Anthopoulos, T. D.; Heeney, M. Macromolecules 2015, 48, 5605.

(53) Pal, B.; Yen, W.; Yang, J.; Chao, C.; Hung, Y.; Lin, S.; Chuang, C.; Chen, C.; Su, W. Macromolecules 2008, 81, 6664.

(54) Zhang, W.; Smith, J.; Watkins, S.; Gysel, R.; Mcgehee, M.; Salleo, A.; Kirkpatrick, J.; Ashraf, S.; Anthopoulos, T. D.; Heeney, M.; McCulloch, I. J. Am. Chem. Soc. 2010, 132, 11437.

(55) Endo, K.; Ohkubo, T.; Hirokami, M.; Shibata, T. J. Am. Chem. Soc. 2010, 132, 11033.

(56) Lee, J. C. H.; McDonald, R.; Hall, D. G. Nat. Chem. 2011, 3, 894.

(57) Li, H.; Zhang, Z.; Shangguan, X.; Huang, S.; Chen, J.; Zhang, Y.; Wang, J. Angew. Chem. Int. Ed. 2014, $53,11921$.

(58) Endo, K.; Ishioka, T.; Shibata, T. Synlett 2014, 25, 2184.

(59) Venkateshvaran, D.; Nikolka, M.; Sadhanala, A.; Lemaur, V.; Zelazny, M.; Kepa, M.; Hurhangee, M.; Kronemeijer, A. J.; Pecunia, V.; Nasrallah, I.; Romanov, I.; Broch, K.; Mcculloch, I.; Emin, D.; Olivier, Y.; Cornil, J.; Beljonne, D.; Sirringhaus, H. Nature 2014, 515, 384.

(60) Deng, Y.; Chen, Y.; Zhang, X.; Tian, H.; Bao, C.; Yan, D.; Geng, Y.; Wang, F. Macromolecules 2012, $45,8621$.

(61) Marszalek, T.; Li, M.; Pisula, W. Chem. Commun. 2016, 52, 10938.

(62) Zhang, M.; Tsao, H. N.; Pisula, W.; Yang, C.; Mishra, A. K.; Mu, K. J. Am. Chem. Soc. 2007, 129, 3472.

(63) Kang, I.; An, T. K.; Hong, J. a.; Yun, H. J.; Kim, R.; Chung, D. S.; Park, C. E.; Kim, Y. H.; Kwon, S. K. Adv. Mater. 2013, 25, 524.

(64) Earmme, T.; Hwang, Y. J.; Murari, N. M.; Subramaniyan, S.; Jenekhe, S. A. J. Am. Chem. Soc. 2013, $135,14960$.

(65) Dou, L.; Chang, W. H.; Gao, J.; Chen, C. C.; You, J.; Yang, Y. Adv. Mater. 2013, $25,825$.

(66) Uy, R. L.; Yan, L.; Li, W.; You, W. Macromolecules 2014, 47, 2289. 
(67) Hendriks, K. H.; Li, W.; Wienk, M. M. J. Am. Chem. Soc. 2014, 136, 12130.

(68) Warnan, J.; El Labban, A.; Cabanetos, C.; Hoke, E. T.; Shukla, P. K.; Risko, C.; Brédas, J. L.; McGehee, M. D.; Beaujuge, P. M. Chem. Mater. 2014, 26, 2299.

(69) Patra, A.; Bendikov, M. J. Mater. Chem. 2010, 20, 422.

(70) Keshtov, M. L.; Kuklin, S. A.; Radychev, N. A.; Nikolaev, A. Y.; Koukaras, E. N.; Sharma, A.; Sharma, G. D. $R S C A d v$. 2016, 14893.

(71) Hai, J.; Shi, G.; Yu, J.; Zhu, E.; Bian, L.; Ma, W.; Tang, W. New J. Chem. 2014, 38, 4816.

(72) Li, W.; Hendriks, K. H.; Furlan, A.; Zhang, A.; Wienk Bc, M. M.; Janssen, R. A. J. Chem. Commun. 2015, 4290, 4290.

(73) Keshtov, M. L.; Kuklin, S. A.; Radychev, N. A.; Nikolaev, A. Y.; Ostapov, I. E.; Krayushkin, M. M.; Konstantinov, I. O.; Koukaras, E. N.; Sharma, A.; Sharma, G. D. Phys. Chem. Chem. Phys. 2016, 18, 8389.

(74) Zhou, E.; Cong, J.; Hashimoto, K.; Tajima, K. Energy Environ. Sci. 2012, 5, 9756.

(75) Jung, J. W.; Liu, F.; Russell, T. P.; Jo, W. H. Energy Environ. Sci. 2012, 5, 6857.

(76) Tsao, H. N.; Cho, D. M.; Park, I.; Hansen, M. R.; Mavrinskiy, A.; Yoon, D. Y.; Graf, R.; Pisula, W.; Spiess, H. W.; Müllen, K. J. Am. Chem. Soc. 2011, 133, 2605.

(77) Wang, S.; Kappl, M.; Liebewirth, I.; Müller, M.; Kirchhoff, K.; Pisula, W.; Müllen, K. Adv. Mater. 2012, 24, 417.

(78) Yamashita, Y.; Tsurumi, J.; Hinkel, F.; Okada, Y.; Soeda, J.; Zaja,czkowski, W.; Baumgarten, M.; Pisula, W.; Matsui, H.; Müllen, K.; Takeya, J. Adv. Mater. 2014, 26, 8169.

(79) Pattanasattayavong, P.; Promarak, V.; Anthopoulos, T. D. Adv. Electron. Mater. 2017, 3, 1600378.

(80) Wijeyasinghe, N.; Anthopoulos, T. D. Semicond. Sci. Technol. 2015, 30, 104002.

(81) Niedzialek, D.; Lemaur, V.; Dudenko, D.; Shu, J.; Hansen, M. R.; Andreasen, J. W.; Pisula, W.; Müllen, K.; Cornil, J.; Beljonne, D. Adv. Mater. 2013, 25, 1939.

(82) Tsao, H. N.; Cho, D.; Andreasen, J. W.; Rouhanipour, A.; Breiby, D. W.; Pisula, W.; Müllen, K. Adv. Mater. 2009, 21, 209.

(83) Pattanasattayavong, P.; Yaacobi-Gross, N.; Zhao, K.; Ndjawa, G. O. N.; Li, J.; Yan, F.; O’Regan, B. C.; Amassian, A.; Anthopoulos, T. D. Adv. Mater. 2013, 25, 1504. 
1

2

3

4

5

6

7

8

9

10

11

12

13

14

15

16

17

18

19

20

21

22

23

24

25

26

27

28

29

30

31

32

33

34

35

36

37

38

39

40

41

42

43

44

45

46

47

48

49

50

51

52

53

54

55

56

57

58

59

60
Table of Contents

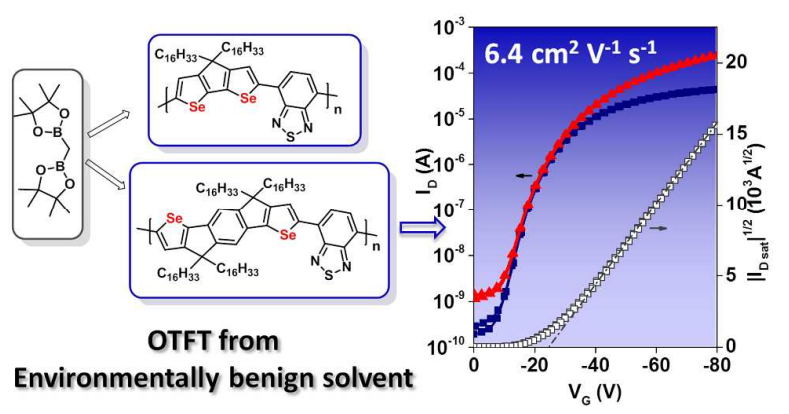

